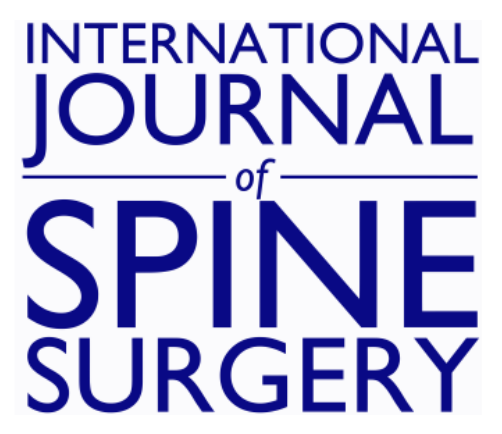

\title{
Comparison of 2-Level Versus 1-Level Total Disc Replacement: Results From a Prospective FDA-Regulated Trial
}

Jack E. Zigler and Donna D. Ohnmeiss

Int J Spine Surg 2008, 2 (3) 140-144

doi: https://doi.org/10.1016/SASJ-2008-0009-RR

http://ijssurgery.com/content/2/3/140

This information is current as of April 25, 2023.

Email Alerts Receive free email-alerts when new articles cite this article. Sign up at: http://ijssurgery.com/alerts 


\title{
Comparison of 2-Level Versus 1-Level Total Disc Replacement: Results From a Prospective FDA-Regulated Trial
}

\author{
Jack E. Zigler, MD, a and Donna D. Ohnmeiss, DrMed ${ }^{b}$
}

\begin{abstract}
Background

Fusion has been the traditional surgery for painful disc degeneration unresponsive to nonoperative care. Fusion rates may decline in multilevel procedures. Also, fusion may force additional stress onto adjacent discs. This effect may be amplified in multilevel procedures. Single-level total disc replacement (TDR) has been found to be as effective as fusion. There have been few published reports addressing 2-level TDR. The purpose of this study was to compare results of TDR at 2 levels to 1-level procedures.
\end{abstract}

\begin{abstract}
Methods
This report included the first consecutive 86 patients who had reached 24-month follow-up from among those enrolled in the ProDisc-L investigational device exemption (IDE) study of patients undergoing TDR at 1 level $(\mathrm{N}=54)$ or at 2 levels $(\mathrm{N}=32)$. Clinical outcome measures included visual analog scales (VAS) assessing pain, Oswestry Disability Index, satisfaction measured by VAS, and responses to the question regarding whether the patient would have the same surgery again.

\section{Results}

Operative time and length of hospitalization were significantly less in the 1-level cases compared to 2 levels (61.6 min vs 97.8 $\mathrm{min}$; and 1.89 days vs 2.44 days; $\mathrm{P}<.05)$. There was a trend for less blood loss in single-level cases $(59.0 \mathrm{~mL}$ vs $79.2 \mathrm{~mL})(.05$ $<\mathrm{P}<.09$ ). VAS and Oswestry scores were significantly improved in both groups postoperatively (by approximately $50 \%$ ). At no follow-up were there significant differences in VAS, Oswestry, or patient satisfaction scores between the single- and 2-level patients. At all follow-ups, the mean satisfaction in both groups was greater than 7.5 on a scale of 0 to 10 .
\end{abstract}

\section{Conclusions}

Patients undergoing 2-level TDR improved significantly postoperatively based on VAS and Oswestry scores, and there were no significant differences in outcome scores when comparing 1- and 2-level TDR.

\section{Clinical Relevance}

This study suggests that 2-level TDR can be undertaken in appropriately selected patients and achieve results similar to singlelevel cases.

Key Words: Total disc replacement, lumbar spine, disc degeneration, clinical outcome, ProDisc-L. SAS Journal. Summer 2008;2:140-144. DOI: SASJ-2008-0009-RR

${ }^{a}$ Texas Back Institute; ${ }^{\mathrm{b}}$ Texas Back Institute Research Foundation, Plano, Texas

Address correspondence to Dr. Jack Zigler, Texas Back Institute, 6020 W. Parker Rd. \#200, Plano, Texas 75093

Dr. Jack Zigler is a consultant to Synthes Spine and has received support for travel/speaking. Dr. Ohnmeiss is employed by a foundation that receives fellowship program support from Synthes Spine.

Institutional Review Board approval was obtained prior to the initiation of this study.

\section{INTRODUCTION}

In the treatment of painful disc degeneration, lumbar spinal fusion has been the primary treatment after patients have not gained acceptable relief from nonoperative measures. While the results have been acceptable, the percentage of patients who experience good outcomes appears to hit a ceiling of about $75 \%$, regardless of the innovations in fusion technique made during an approximate 20 -year period. ${ }^{1}$ These results are undoubtedly influenced by a variety of factors including the specific surgical technique, surgeon skill and experience, patient personality, and the specific origin of each patient's symptoms. Some studies have reported that fusion rates decrease, or that there is at least a trend for such, as the number of operated levels increases. ${ }^{2-4}$ This decline in fusion rates may lead to less-desirable clinical outcomes in patients undergoing fusion for multilevel degenerative disc disease.

One of the potential advantages of TDR over fusion is a reduction in the likelihood of accelerating the degeneration of the transitional adjacent segment. While the impact of adjacent segment degeneration is not yet consistently described clinically, ${ }^{5-10}$ there are biomechanical studies supporting that fusion increases the pressure within the adjacent disc.11-15. It has also been reported that progressively greater changes in 
lumbar segment kinematics correlate with a greater number of instrumented levels. ${ }^{16,17}$ Computer modeling has found that the stress on the disc adjacent to an interbody fusion increases with the number of levels fused. ${ }^{18}$ These studies suggest that 2-level fusion may have a greater potential for detrimental consequences at adjacent discs.

While the results of TDR have been found to be favorable in most studies, ${ }^{19-26}$ there has been little investigation of 2level TDR. One article reviewed 10 2-level and 15 3-level TDR procedures ${ }^{19}$ and another noted results of 13 multilevel cases, including 112 -level procedures. ${ }^{20}$ While the results in these series were favorable, they represent a relatively small number of patients. The purpose of this study was to evaluate the outcome of 2-level TDR and to compare the results to single-level procedures using the same implant.

\section{MATERIALS AND METHODS}

The study was based on the consecutive series of the first 86 patients undergoing TDR with ProDisc-L (Synthes Spine, West Chester, Pennsylvania) at one center as part of an FDA-regulated clinical trial. There were 32 2-level disc replacements and 54 single-level replacements. All procedures were performed using a retroperitoneal approach to the lumbar spine. The only demographic difference identified between the 2 groups was that the mean age was significantly greater among patients undergoing 2-level replacement (Table 1). All patients were treated for symptomatic disc degeneration unresponsive to a minimum of six months of nonoperative care. All patients had undergone MRI and the majority had discograms. Only patients with a score of at least $40 \%$ on the Oswestry Disability Index were included. Patients with greater than Grade I spondylolisthesis, previous lumbar fusion, or clinically relevant facet joint changes were excluded from study enrollment.

Data were collected preoperatively, perioperatively, and postoperatively at 6 weeks, and at $3,6,12,18$, and 24 months. Only patients who reached a minimum 24-month follow-up were included in this study. Outcome data included visual analog scale (VAS) assessing pain, Oswestry Disability Index, ${ }^{27}$ patient satisfaction (VAS ranging from 0 to 10 ), and patient responses to whether they would have the same surgery again.

\section{Data Analysis}

Means were compared between the 2 groups using independent $t$-tests and change in preoperative to postoperative mean scores on the VAS and Oswestry were compared using paired $t$-tests. Chi-square analyses were used to compare proportional data. Statistical analyses were performed using SPSS software (Chicago, Illinois).

\section{RESULTS}

\section{Perioperative Data}

Operative time and length of hospitalization were significantly less in the 1-level cases compared to the 2-level cases (Table
2). The additional level required approximately 30 minutes of operative time. There was also a trend for less blood loss in single-level cases, although the difference was not significant.

Table 1. Descriptives of the 1- and 2-Level TDR Subgroups

1-Level 2-Level

$(n=54) \quad(n=32) \quad$ Significance

\begin{tabular}{lrrr} 
Gender & & & $P>.70$ \\
Male & $53.7 \%$ & $53.1 \%$ & \\
Female & $46.3 \%$ & $46.9 \%$ & \\
\hline Age (years): & & & $P<.05$ \\
Mean & 38.0 & 43.9 & \\
Range & $19-57$ & $28-59$ & \\
\hline Levels Operated & & & $\mathrm{N} / \mathrm{A}$ \\
L3-4 & $3.7 \%$ & $\mathrm{~N} / \mathrm{A}$ & \\
L4-5 & $33.3 \%$ & $\mathrm{~N} / \mathrm{A}$ & \\
L5-S1 & $63.0 \%$ & $\mathrm{~N} / \mathrm{A}$ & \\
L3-4 \& L4-5 & $\mathrm{N} / \mathrm{A}$ & $12.5 \%$ & \\
L4-5 \& L5-S1 & $\mathrm{N} / \mathrm{A}$ & $87.5 \%$ & \\
\hline Smoking & & & $P>.60$ \\
Smoker & $35.2 \%$ & $34.4 \%$ & \\
Non-smoker & $64.8 \%$ & $65.6 \%$ & \\
\hline Previous Surgery & & & $P>.60$ \\
Yes & $33.3 \%$ & $37.5 \%$ & \\
No & $66.7 \%$ & $62.5 \%$ & \\
\hline Insurance & & & $P>.60$ \\
Private Insurance & $79.2 \%$ & $74.2 \%$ & \\
WC & $20.7 \%$ & $25.8 \%$ & \\
\hline
\end{tabular}

The only significant difference was the mean age in the 2-level cases was significantly greater.

Table 2. Perioperative Data for 1-Level and 2-Level Subgroups

\begin{tabular}{lrrr}
\hline & 1-Level & 2-Level & Significance \\
\hline Blood loss $(\mathrm{ml})$ & 59.0 & 79.2 & $.05<P<.09$ \\
\hline Operative time $(\mathrm{min})$ & 61.9 & 97.8 & $P<.001$ \\
\hline $\begin{array}{l}\text { Length of } \\
\text { hospitalization (days) }\end{array}$ & 1.89 & 2.44 & $P<.05$ \\
\hline
\end{tabular}

The mean blood loss, operative time and length of hospitalization were all less in single-level cases $(P<.05 ; t$-test $)$.

\section{VAS Pain Scores}

VAS scores assessing pain improved significantly in both groups from preoperative to postoperative measurements. The improvement was approximately $50 \%$ (Figure 1 ). At no visit was there a significant difference in mean VAS score between the 1-level and 2-level groups. 


\section{Figure 1.}

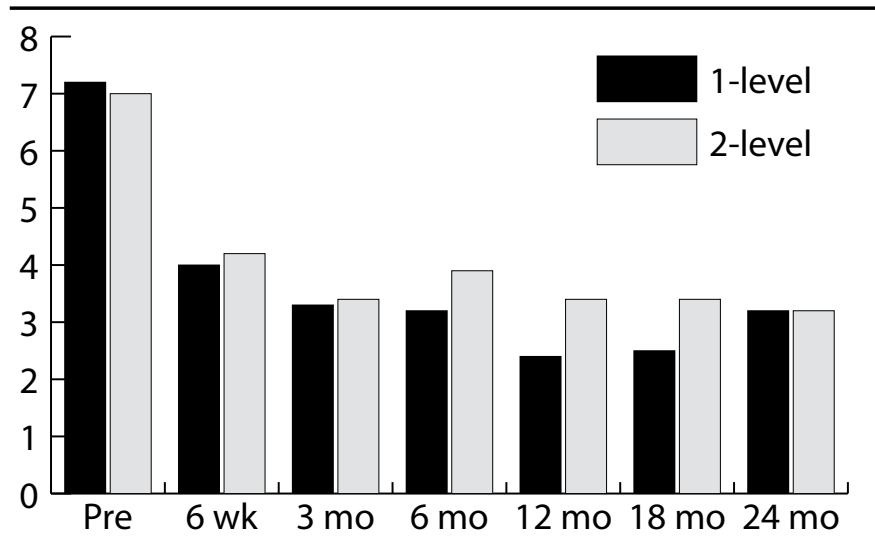

The mean post-op VAS pain scores were significantly improved in both the 2-level and the 1-level groups $(P<.05)$. There was no significant difference in the mean scores between the groups at any evaluation period $(P>.15)$.

\section{Oswestry Disability Scores}

The Oswestry scores followed a pattern similar to the VAS scores. The postoperative Oswestry scores improved significantly compared with the preoperative scores in both groups (Figure 2), with no significant differences between groups at any of the evaluation periods.

\section{Figure 2.}

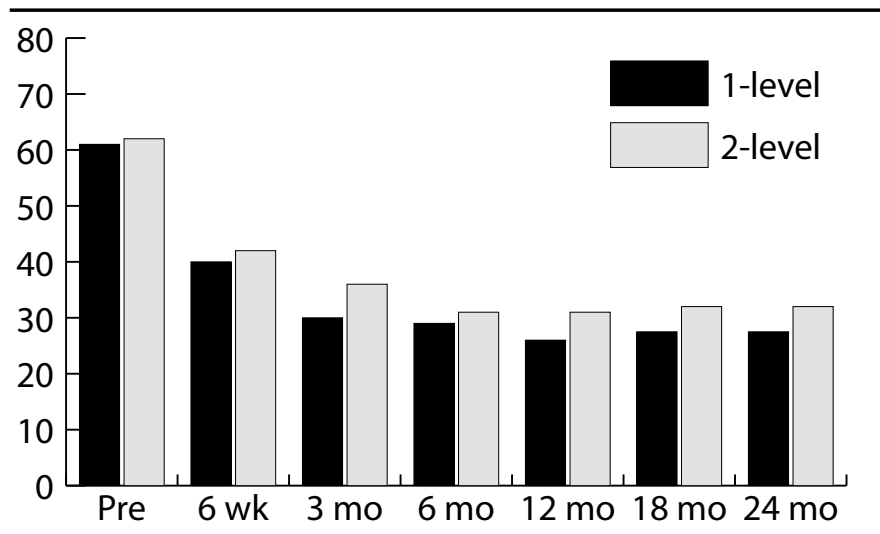

The mean Oswestry scores improved significantly in both groups $(P<.05)$. At none of the evaluation periods was there a significant difference in the mean scores between the two groups $(P>.15)$.

\section{Patient Satisfaction}

Patient satisfaction was assessed using 2 different methods. A 10-point VAS was completed at each follow-up visit, with greater scores indicating greater satisfaction. As seen in Figure 3 , presenting the mean VAS satisfaction scores, patients in both groups indicated a high level of satisfaction. There were no significant differences between the 2 groups. As a second measure of patients' satisfaction, patients were asked if they would have the same surgery again and were instructed to select from the responses "yes," "no," or "maybe." A high percentage of patients in both the 1- and 2-level replacements groups responded favorably when asked if they would have the treatment again (Figure 4).

Figure 3.

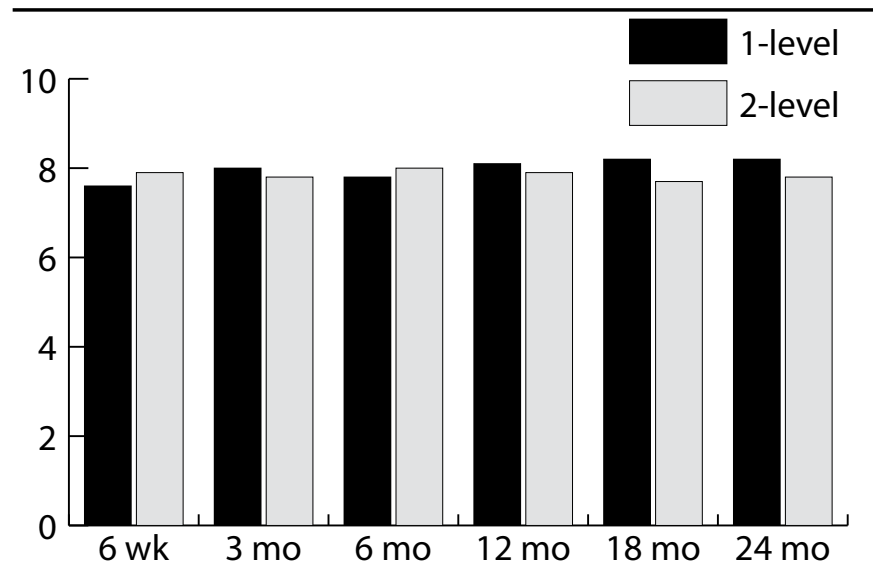

The mean satisfaction scores were very similar in the 1- and 2-level groups at all follow-up periods as assessed by a 0-10 point VAS with greater scores indicating greater satisfaction $(P>.30)$.

Figure 4.

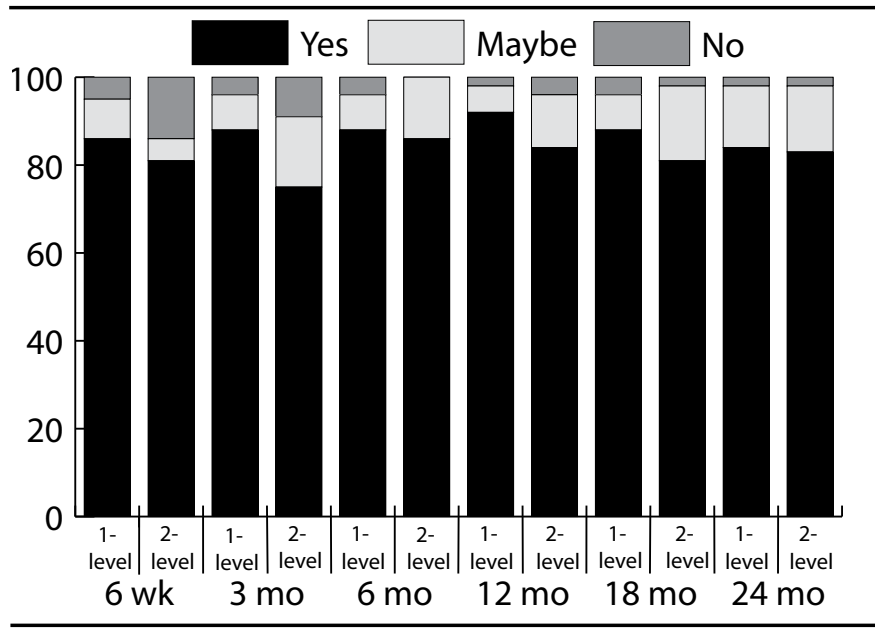

There was no significant difference in the proportional distribution of responses to the question, "Would you have the same treatment again?" $(P>.25)$ when comparing 1-vs 2 -level TDR.

\section{DISCUSSION}

This study found that clinical results of TDR were not diminished as the number of operated levels increased from 1 to 2 adjacent levels in the lower lumbar spine. Perioperative data indicated that 2-level TDR was associated with statistically significantly greater operative time and length of hospitalization. The addition of the second level required approximately 30 minutes more than the single-level replacements. The mean operative times in our series were quite a bit less than those reported by Bertagnoli et al. using the same implant for 1- and 2-level procedures (median of 81 minutes for 1-level and 135 minutes for 2-level). ${ }^{19,20}$ The 
difference may be related to operative technique including the approach used to gain access to the anterior lumbar spine.

Our clinical outcomes for single-level cases were similar to those reported in other TDR trials involving single-level TDR. ${ }^{19,28}$ Although Bertagnoli et al. reported median values, rather than mean values, the outcome scores in their series of 10 patients undergoing 2-level TDR appear to be similar to the 2-level cases in our larger series. ${ }^{29}$ Collectively these studies indicate that there is stability in the published clinical outcomes of TDR.

In a study of patients who underwent fusion for spondylolisthesis, Wimmer et al. reported that the incidence of translation at the segment adjacent to a fusion was greater among patients with multilevel fusions compared to singlelevel fusion. ${ }^{30}$ Another study reported that the number of levels fused was not related to a greater rate of reoperation at the adjacent segment. ${ }^{5}$ However, as the authors discussed, in single-level cases, there were more levels at risk of reoperation than in multilevel fusions. Also those authors noted a trend for reoperation at an adjacent segment that was degenerating at the time of the index surgery. This may have also skewed the data concerning reoperation (if only one of several degenerated discs was operated, this may have artificially increased the reoperation rate for single-level index cases, making it similar to the reoperation rate in multilevel cases).

The results of previous studies investigating adjacent segment deterioration, as well as their designs and populations studied, vary greatly ${ }^{5-10}$ Biomechanical studies and computer modeling have consistently found altered kinematics and increased disc pressure at segments adjacent to a fusion. ${ }^{11-15}$ In additional, some data suggest that kinematics and disc pressure worsen as the number of fused segments increases. ${ }^{16-18}$ The impact of dynamic stabilization on adjacent segment deterioration has yet to be the topic of sufficient investigation. However, one report, using the Graf system, did find that this motionsparing technology was associated with a decreased rate of adjacent segment deterioration compared to fusion. ${ }^{31}$ Recent biomechanical studies in the cervical spine found that, unlike fusion, TDR did not alter the kinematics of the adjacent motion segment and it did not increase intradiscal pressure. ${ }^{32,33}$ Similar results were found in a study of the lumbar spine. ${ }^{34}$ More biomechanical studies as well as clinical data are needed to determine of TDR can have a similar protective impact in the lumbar spine, particularly in multilevel procedures.

The results of this prospective study suggest that 2-level TDR with ProDisc-L is an effective treatment for 2-level symptomatic disc degeneration in appropriately selected patients with pain unresponsive to nonoperative care. While the additional level did increase operative time and length of hospitalization, the clinical outcomes were as favorable as single-level procedures.
This manuscript was submitted June 14, 2008, and accepted for publication August 11, 2008.

\section{REFERENCES}

1. Bono C, Lee CK. Critical analysis of trends in fusion for degenerative disc disease over the past 20 years: Influence of technique on fusion rate and clinical outcome. Spine. 2004;29:455-463.

2. Loguidice VA, Guyer RD, Stith WJ, et al. Anterior lumbar interbody fusion. Spine. 1988;13:366-369.

3. Schiffman M, Brau SA, Henderson R, Gimmestad G. Bilateral implantation of low-profile interbody fusion cages: subsidence, lordosis, and fusion analysis. Spine J. 2003;3:377-387.

4. Fritzell P, Hagg O, Wessberg P, Nordwall A. chronic low back pain and fusion: a comparison of three surgical techniques: A prospective multicenter randomized study from the Swedish Lumbar Spine Study Group. Spine. 2002;27:1131-1141.

5. Ghiselli G, Wang JC, Bhatia NN, et al. Adjacent segment degeneration in the lumbar spine. J Bone Joint Surg. 2004;86-A:1497-1503.

6. Kumar MN, Baklanov A, Chopin D. Correlation between sagittal plane changes and adjacent segment degeneration following lumbar spine fusion. Eur Spine J. 2001;10:314-319.

7. Lee CK. Accelerated degeneration of the segment adjacent to a lumbar fusion. Spine. 1988;13:375-377.

8. Guigui P, Wodecki P, Bizot P, et al. Long term influence of associated arthrodesis on adjacent segments in the treatment of lumbar stenosis: A series of 127 cases with 9-year follow-up. Rev Chir Orthop Reparatrice Appar Mot. 2000;86:546-557.

9. Penta M, Sandhu A, Fraser RD. Magnetic resonance imaging assessment of disc degeneration 10 years after anterior lumbar interbody fusion. Spine. 1995;20:743-747.

10. Rahm MD, Hall BB. Adjacent-segment degeneration after lumbar fusion with instrumentation: a retrospective study. J Spinal Disord. 1996;9:392-400.

11. Lee CK, Langrana NA. Lumbosacral spinal fusion. A biomechanical study. Spine. 1984;9:574-581.

12. Weinhoffer SL, Guyer RD, Herbert M, Griffith SL. In-vitro intradiscal pressure measurements above a simulated instrumented fusion. Spine. 1995;20:526-531.

13. Cunningham BW, Kotani Y, McNulty PS, et al. The effect of spinal destabilization and instrumentation on lumbar intradiscal pressure: an in vitro biomechanical analysis. Spine. 1997;22:2655-2663.

14. Goto K, Tajima N, Chosa E, et al. Effects of lumbar spinal fusion on the other lumbar intervertebral levels (three-dimensional finite element analysis). J Orthop Sci. 2003;8:577-584.

15. Sudo H, Oda I, Abumi K, et al. In vitro biomechanical effects of reconstruction on adjacent motion segment: comparison of aligned/ kyphotic posterolateral fusion with aligned posterior lumbar interbody fusion/posterolateral fusion. J Neurosurg Spine. 2003;99:221-228. 
16. Shono Y, Kaneda K, Abumi K, et al. Stability of posterior spinal instrumentation and its effects on adjacent motion segments in the lumbosacral spine. Spine. 1998;23:1550-1558.

17. Cunningham BW, Gordon JD, Dmitriev AE, et al. Biomechanical evaluation of total disc replacement arthroplasty: an in vitro human cadaveric model. Spine. 2003;28(20 Suppl):S110-117.

18. Chen CS, Cheng CK, Liu CL, Lo WH. Stress analysis of the disc adjacent to interbody fusion in lumbar spine. Med Eng Phys. 2001;23:483-491.

19. Blumenthal SL, McAfee PC, Guyer RD, et al. Aprospective, randomized, multi-center FDA IDE study of lumbar total disc replacement with the CHARITÉTM Artificial Disc vs. lumbar fusion: Part I - evaluation of clinical outcomes. Spine. 2005;30:1565-1575.

20. Tropiano P, Huang RC, Girardi FP, Marnay T. Lumbar disc replacement preliminary results with ProDisc II after a minimum follow-up period of 1 year. J Spinal Disord Tech. 2003;16;362-368.

21. Zeegers WS, Bohnen LMLJ, Laaper M, Verhaegen MJAL. Artificial disc replacement with the modular type SB Charité III: 2-year results in 50 prospectively studied patients. Eur Spine J.1999;8:210-217.

22. Lemaire JP, Carrier H, Ali ES, et al. Clinical and radiological outcomes with the Charite'TM Artificial Disc: A 10-year minimum follow-up. $J$ Spinal Disord Tech. 2005;18:353-359.

23. Mayer HM, Wiechert K, Korge A, Qose I. Minimally invasive total disc replacement: Surgical technique and preliminary clinical results. Eur Spine J. 2002;11 (Suppl 2):S124-130.

24. Delamarter RB, Fribourg DM, Kanim LEA, Bae H. ProDisc artificial total lumbar disc replacement: introduction and early results from the United States clinical trial. Eur Spine J. 2002;28(Suppl 20S):S167175.

25. Zigler JE, Vialle EN, Burd TA, et al. Lumbar spine arthroplasty: Early results using the ProDisc II- A prospective randomized trial of arthroplasty versus fusion. J Spinal Disord Tech. 2003;16:352-361.

26. Zigler JE. Lumbar spine arthroplasty using the ProDisc II. Spine J. 2004;4(6 Suppl):260S-267S

27. Fairbank JC, Pynsent PB. The Oswestry Disability Index. Spine. 2000;25:2940-2952.

28. Bertagnoli R, Yue JJ, Shah RV, et al. The treatment of disabling singlelevel lumbar discogenic low back pain with total disc arthroplasty utilizing the Prodisc prosthesis: A prospective study with 2-year minimum follow-up. Spine. 2005;30:2230-2236.

29. Bertagnoli R, Yue JJ, Shah RV, et al. The treatment of disabling multilevel lumbar discogenic low back pain with total disc arthroplasty utilizing the ProDisc prosthesis: A prospective study with 2-year minimum follow-up. Spine. 2005;30:2192-2199.

30. Wimmer C, Gluch H, Krismer M, et al. AP-translation in the proximal disc adjacent to lumbar spine fusion: a retrospective comparison of mono- and polysegmental fusion in 120 patients. Acta Orthop Scand. 1997;68:269-272.

31. Kanayama M, Hashimoto T, Shigenobu K, et al. Adjacent-segment morbidity after Graf ligamentoplasty compared with posterolateral lumbar fusion. J Neurosurg. 2001;95(1 Suppl):5-10.

32. Dmitriev AE, Cunningham BW, Hu N, et al. Adjacent level intradiscal pressure and segmental kinematics following a cervical total disc arthroplasty: an in vitro human cadaveric model. Spine. 2005;30:11651172.
33. DiAngelo DJ, Roberston JT, Metcalf NH, et al. Biomechanical testing of an artificial cervical joint and an anterior cervical plate. J Spinal Disord Tech. 2003;16:314-323.

34. Cunningham BW, Gordon JD, Dmitriev AE, et al. Biomechanical evaluation of total disc replacement arthroplasty: an in vitro human cadaveric model. Spine. 2003;28(Suppl 20S):S110-117. 